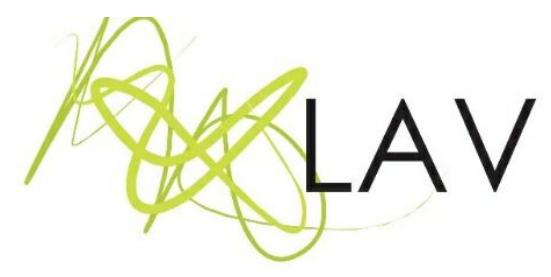

\title{
Reflexões sobre o uso de games no ensino de arte a partir do artista, jogador, professor e aluno
}

\author{
Reflections on the use of games in Arts teaching by the artist, player, teacher, and \\ student
}

José Loures'

Instituto Federal de Educação, Ciência e Tecnologia São Paulo

\section{RESUMO}

O presente artigo apresenta reflexões sobre as perspectivas da utilização de jogos digitais no ensino de Artes. O trabalho é dividido em experiências e vivências onde o papel de artista, jogador, professor e aluno convergem. O texto pretende apresentar uma perspectiva de relato pessoal sobre os processos, possibilidades e desafios para o professor que busca aplicar os games no ensino-aprendizagem em Artes Visuais. Nesse contexto, abordo autores que são referências perante essas perspectivas: As possibilidades criativas da gamearte por meio de Lúcia Leão (2005), Suzete Venturelli e Mário Maciel (2004); a importância e presença dos jogos na cultura através de Johan Huizinga (2013); para as possibilidades dos jogos digitais no ensino com Lynn Alves (2008) e Jaderson Souza (2016); a imersão e interatividade presente nos jogos digitais com Oliver Grau (2007), Gustavo Audi (2016), Alexandre Carrieri e Pablo Gobira (2012); Stuart Hall (1997), Zygmunt Bauman (2003) e Vilém Flusser (1963) para discutir o contato com o outro. E, por fim, para abordar experiências e problematizações acerca do ensino de Artes Visuais com jogos digitais apresento Christus Nóbrega et al. (2011).

Palavras-chave: artes visuais, videogames, autobiografia, ensino-aprendizagem.

\section{ABstract}

The present article presents reflections on perspectives of the use of digital games in Arts teaching. This research explores experiences where the roles of artist, player, teacher, and student converge. The text presents a personal report about processes, possibilities, and challenges for the teacher who applies games for the teaching-learning of Visual Arts. In this context, authors who are references in the following perspectives are approached: The creative possibilities of gameart from Lúcia Leão (2005), Suzete Venturelli and Mario Maciel (2007); the relevance and presence of games in culture from Johan Huizinga (2013); the possibilities of digital games in teaching from Lynn Alves (2008) and Jaderson Souza (2016); the current immersion and interactivity in digital games from Oliver Grau (2007), Gustavo Audi (2016), Alexandre Carrieri and Pablo Gobira (2012); Stuart Hall (1997), Zygmunt Bauman (2003), and Vilém Flusser (1963) in order to discuss the contact with others. Furthermore, Christus Nóbrega et al. (2011) are presented, to approach experiences and problematizations on teaching Visual Arts with digital games.

Keywords: visual arts, video games, autobiography, teaching-learning. 


\section{Introdução}

Os jogos digitais ou games como também são conhecidos estão se inserindo cada vez mais em nosso cotidiano, e isso acontece devido à crescente utilização dos videogames - aparelhos eletrônicos criados para a interação entre o usuário (jogador) e software (jogo digital), computadores pessoais com o objetivo de jogar, e mais recentemente, através dos dispositivos móveis como celulares e tablets. O filósofo Johan Huizinga (2013) vislumbrou os jogos como uma convergência da produção humana. O autor faleceu décadas antes do surgimento dos primeiros games, mas sua teoria se mostra frutífera na contemporaneidade. Para Lynn Alves (2008) os jogos digitais podem atuar como mediadores na construção de conceitos. Para a autora, essas mediações criam formas de vida, sistemas, planejamentos, construção de conteúdos afetivos e comunidades através de simulações sociais e históricas.

Somos sujeitos históricos e, por isso, seres em constante construção (SARDELICH; SANTOS, 2008). Nesse sentido, transitamos entre diferentes papéis ao longo da vida, mas, sobretudo, ocupamos posições diversificadas e simultâneas. Nesse contexto, portanto, a proposta do artigo é partir das minhas vivências e experiências com os jogos digitais nas perspectivas do artista, jogador, professor e aluno. No papel do artista, discuto como a arte contemporânea se apropriou da linguagem dos videogames em seu fazer artístico, a gamearte. No papel de jogador, coloco como as minhas experiências na infância e juventude moldaram meu interesse pelos videogames através da imersão e interação. Já no papel de professor, discuto sobre experiências em sala de aula que dialogam com o processo de contar histórias e como os jogos digitais podem auxiliar nessas narrativas. A maioria dos professores fora formada em uma cultura contemplativa indo contra a tendência de uma cultura cada vez mais imersiva (NÓBREGA et al., 2011). E no papel de aluno, vivenciei o conflito entre gerações e como a tecnologia pode ser usada no ensino.

Assim, discuto, através da união entre relatos pessoais e de autores, como os jogos digitais podem ser utilizados no ensino, bem como suas relações culturais com os educadores, alunos e instituições. Também apresento aspectos importantes como a imersão, interação, narrativa, acesso e diversão, considerando como esses fatores podem auxiliar o professor que deseja aplicar os jogos digitais no ensino-aprendizagem em Artes Visuais.

\section{O artista}

A arte propicia o singular encontro entre o artista e o público, e mesmo que o artista não esteja fisicamente presente para solucionar determinados questionamentos, o 
trabalho artístico cria um diálogo entre o público e o autor. Desde criança, frequento galerias e museus (figura 1 ):

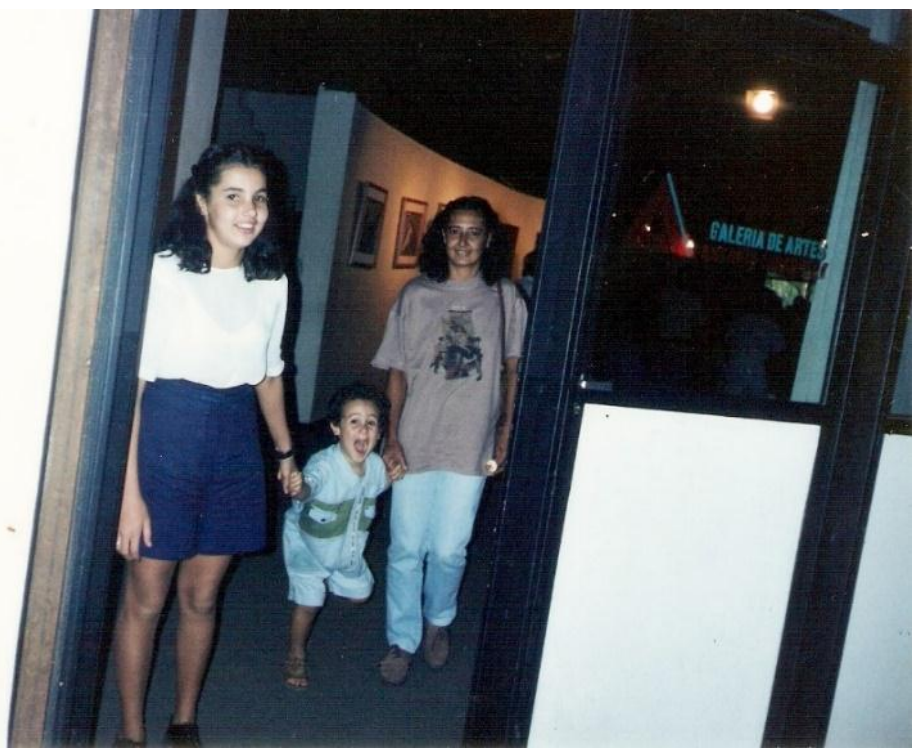

Figura 1: Abertura de exposição na Galeria de Artes Antônio Sibasolly em 1992. Fonte: Acervo do autor.

Meus passeios, quando criança, eram preenchidos de gritos de desespero pela ousadia de insistir em brincar em galerias e museus. Já adulto, em 2010, visitei a exposição "Vertigem", da dupla Os Gêmeos, no Centro Cultural Banco do Brasil em Brasília (figura 2):

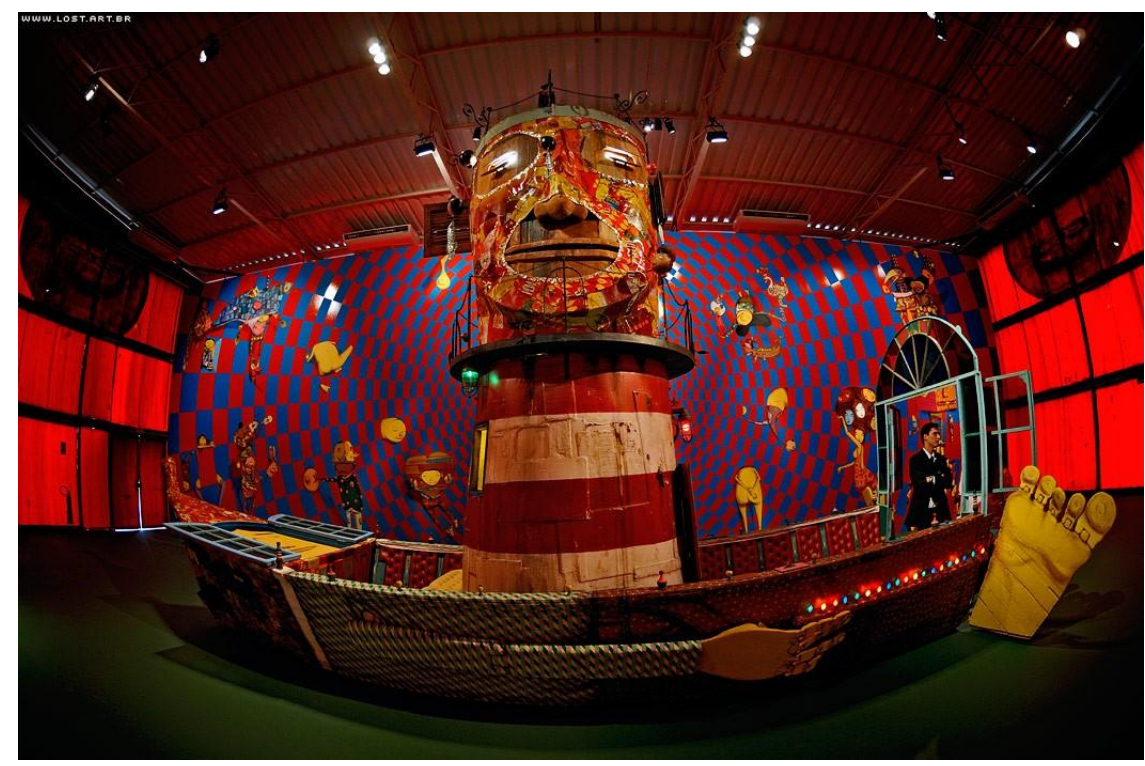

Figura 2: Exposição "Vertigem" no Centro Cultural Banco do Brasil - DF. Fonte: http://www.osgemeos.com.br/pt/projetos/vertigem-ccbb-df/.

Aquelas cores, objetos, sons e os cheiros imploravam para um contato direto com o público. Nesse ambiente estavam presentes figuras vestidas em trajes escuros (os 
seguranças), e que se manifestavam, caso houvesse a mínima vontade de interação com os trabalhos. Nesse contexto, o ambiente das galerias sempre me fascinou, por propiciar o encontro entre artista e público. Ainda que o ambiente se apresentasse opressivo, sisudo, sofrido e insistente em exigir uma seriedade dos frequentadores, com ordens: não toque, não fale, não coma, não beba, ou seja, não exista, pensar esse contexto é particularmente irônico, pois a obra existe a partir do encontro com o outro.

Junto à minha paixão pela arte, outra sempre me acompanhou: os jogos. Então, encontrei nas artes uma possibilidade de apropriação da linguagem desses sistemas lúdicos para o desenvolvimento de poéticas que dialogassem com a contemporaneidade. Esse encontro entre linguagens proporcionou vislumbrar os jogos além de seu ambiente nativo e suas possibilidades artísticas e, posteriormente, educacionais.

\section{A gamearte}

Desde 2010, desenvolvo uma pesquisa sobre os jogos na arte, sendo o meu trabalho, Oitavo Dia (2016), que considero o mais frutífero em jogabilidade e poética (figura 3):

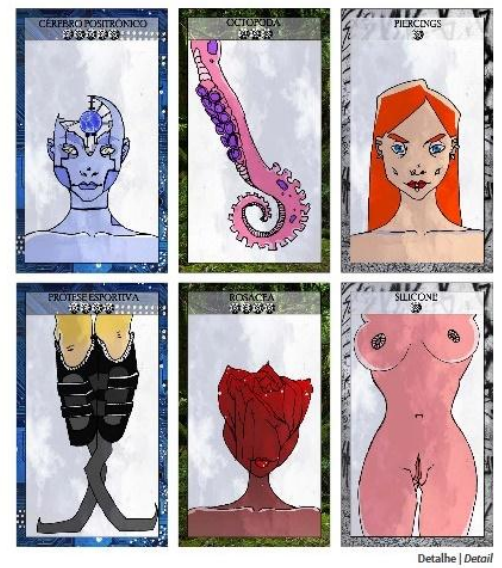

Oitavo Dia. 2016.60 cartas de modificacác corporal, 24 cartas de açá, 30 moedas, dado de 6 faces, tabulein,

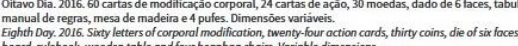

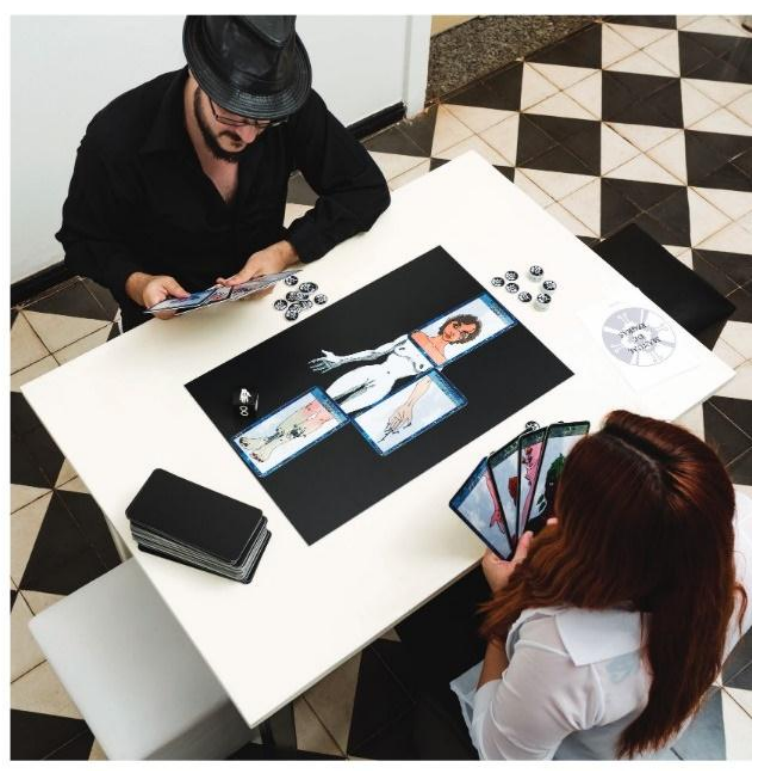

Figura 3: Oitavo Dia.

Fonte: http://cultura.anapolis.go.gov.br/salaodearte/edicoesAnteriores.

A proposta do trabalho discute a opressão midiática que a mulher sofre, muitas vezes se mutilando para alcançar um corpo que acredita ser o ideal e perfeito, feito através

Revista Digital do LAV - Santa Maria - vol. 14, n. 3, p. 27 - 47 - set./dez. 2021 ISSN 1983 - 7348 http://dx.doi.org/10.5902/1983734865845 
de um jogo de tabuleiro em um contexto pós-humano ${ }^{1}$. Nesse jogo, os riscos ficam claros, e as pacientes obcecadas com o sonho de "melhorar" o seu corpo realizam cirurgias que podem resultar em graves sequelas e até a morte. Oitavo Dia parece uma ficção científica, mas como as produções desse gênero, a linguagem ficcional é utilizada como pretexto para se discutir questões e problemas contemporâneos. Em 2016, Oitavo Dia foi um dos quatro trabalhos goianienses selecionados, de um total de 701 inscritos para $022^{\circ}$ Salão Anapolino de Arte (figura 4). Nessa exposição, houve a visitação de 5 mil pessoas, dentre eles, 1,3 mil alunos e professores da rede municipal de Anápolis².

O processo criativo para o desenvolvimento de uma obra de arte e de um jogo possui estruturas semelhantes: regras pré-estabelecidas e a relação entre obra e público (MASTROBERTI, 2019). Nesse sentido, o artista e o desenvolvedor envolvem suas criações em conceitos, poéticas e na expectativa da fruição entre obra e público/usuário. A arte sempre acompanhou as tecnologias de seu tempo, e isso não seria diferente com os jogos. Machado (2007) coloca a arte como um processo que permite ao artista usar quaisquer ferramentas e tecnologias. Nesse contexto, os artistas utilizam da linguagem dos videogames em seu fazer artístico.

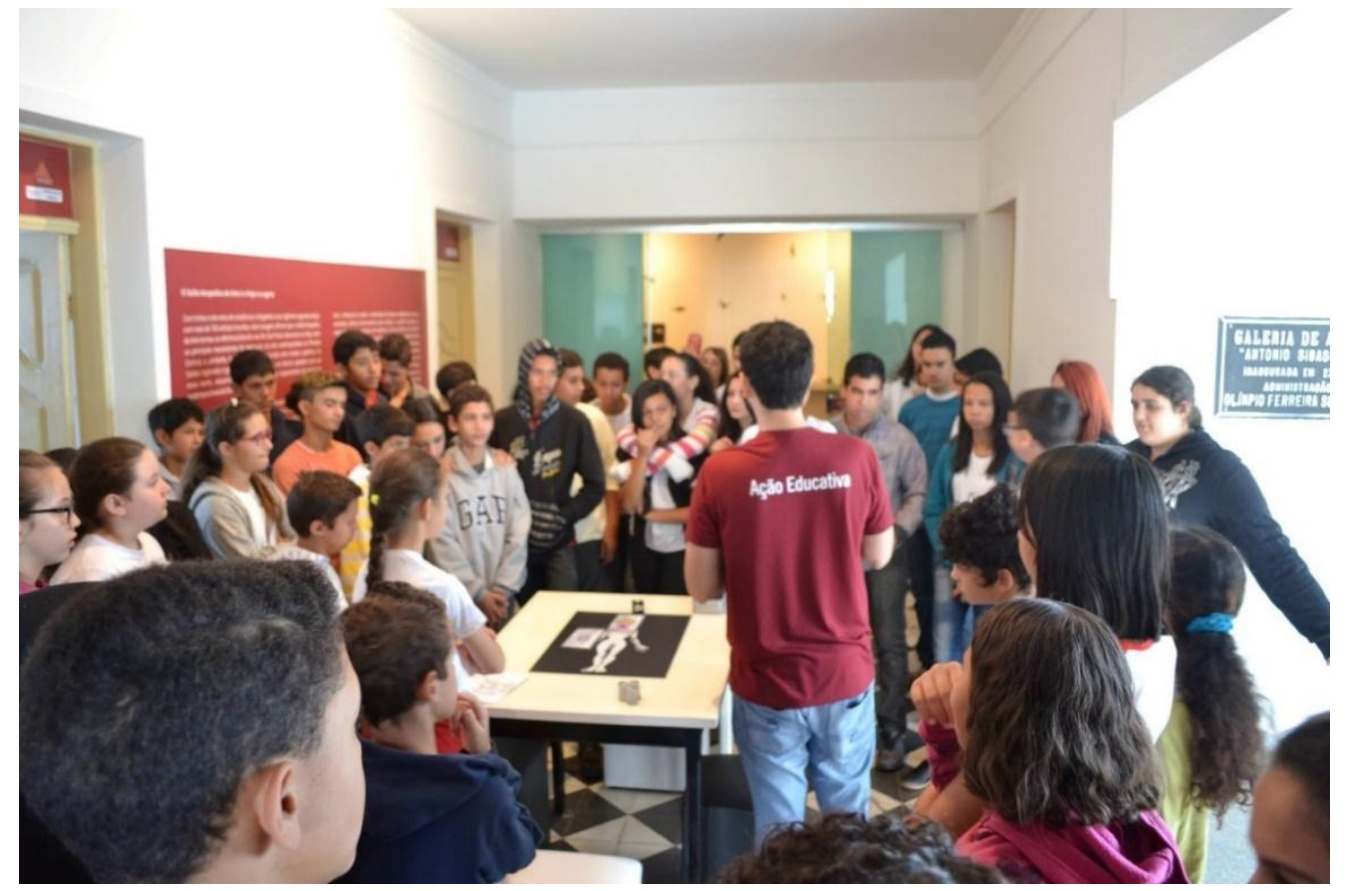

Figura 4: Ação educativa no $22^{\circ}$ Salão Anapolino de Artes.

Fonte: Acervo do autor.

\footnotetext{
${ }^{1} \mathrm{O}$ pós-humanismo é uma corrente filosófica que discute o corpo humano perante as evoluções tecnológicas e a sua possível obsolescência.

${ }^{2}$ Informação coletada através do livro de frequência com a assinatura dos visitantes.
}

Revista Digital do LAV - Santa Maria - vol. 14, n. 3, p. 27 - 47 - set./dez. 2021 ISSN 1983 - 7348 http://dx.doi.org/10.5902/1983734865845 
Para Leão (2005), a gamearte são projetos que se apropriam dos games de maneira questionadora, com o objetivo de subverter as plataformas da cultura gamer. De acordo com Venturelli e Maciel (2004) a própria gamearte é marcada por uma reflexão, em que o lúdico flerta com a desconstrução de modelos sociais.

Mastroberti (2019) parte da premissa que, qualquer jogo pode envolver pensamentos, habilidades e preposições criativas, independentemente da sua função. Para Souza (2016), a estrutura hipermidiática, presente nos jogos digitais, é capaz de gerar fruição para com os jogadores, e, por isso, este pode ser compreendido como objeto de arte. Então, até mesmo os games para o mercado também podem questionar e trazer reflexões ao jogador, assim como os jogos tradicionalmente considerados gamearte.

Por exemplo, os jogos considerados independentes são desenvolvidos e lançados por uma equipe pequena ou até mesmo um único desenvolvedor, e isso permite uma autoralidade na criação de um game. A autoralidade é um conceito artístico, em que o artista se expressa de maneira autobiográfica, ou seja, um processo para a construção de uma obra autoral. Considero a autoralidade como um elemento fundamental para que um jogo possa ser um trabalho de gamearte. Nesse sentido, quando os artistas se apropriam da linguagem dos games, também se abrem portas de entrada para o seu uso nas mais variadas áreas, como o ensino.

\section{O jogador}

O acordo era o seguinte: trocar a chupeta por um Master System III (1986 1996) ${ }^{3}$. Como uma criança sensata, aceitei o acordo de bom grado (figura 5):

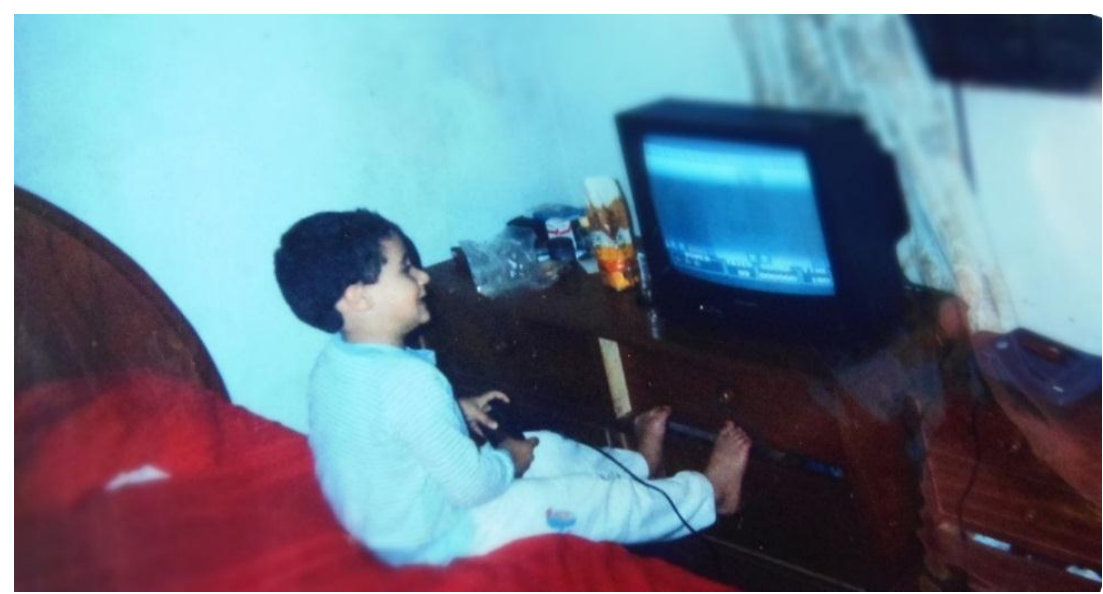

Figura 5: Eu e o Master System III.

Fonte: Acervo do autor.

\footnotetext{
${ }^{3}$ Aqui uso uma marcação de tempo para mostrar o período de início e encerramento da produção de um determinado videogame.
}

Revista Digital do LAV - Santa Maria - vol. 14, n. 3, p. 27 - 47 - set./dez. 2021 ISSN 1983 - 7348 http://dx.doi.org/10.5902/1983734865845 
A possibilidade de me transformar a cada cartucho encaixado no videogame me fascinava. Após um tempo, troquei o aparelho da SEGA - produtora do Master System III, por um Super Nintendo (1990 - 2003), e é aqui que a paixão pelos jogos digitais se expandiu ainda mais. Nos anos 90, o preço de um cartucho novo de Super Nintendo tornava inviável a compra de vários jogos. Devido ao alto custo dos videogames, portanto, surgem as locadoras de jogos. Nesse ambiente, era possível jogar videogame com algumas moedas.

Era necessário acordar cedo para conseguir alugar os jogos mais concorridos e, após isso, passar um final de semana transitando entre vários universos, menos a nossa própria realidade. O tempo passou, o Super Nintendo foi vendido e obtive alguns videogames portáteis da Nintendo, como, por exemplo, o Game Boy Pocket (1996 - 2000), Game Boy Color (1998 - 2003) e Game Boy Advance (2001 - 2009). Apesar das telas pequenas e a baixa qualidade do som, esses aparelhos portáteis foram suficientes para vivenciar diversas possibilidades no papel de jogador.

Na adolescência, consegui um PlayStation (1994 - 2006), e, devido à pirataria, tive acesso a centenas de jogos. Um jogo original de PlayStation, no final da década de 1990 , custava em média $R \$ 80$, e o salário mínimo da época era de $R \$ 136$ (figura 6).

Já um jogo pirateado era comercializado por $\mathrm{R} \$ 10$, ou até por valores mais baratos em camelódromos. No Brasil, o PlayStation ainda tem uma enorme base de fãs e jogadores, que foram alimentados através das facilidades de se adquirir um videogame desbloqueado para jogos piratas em décadas passadas.

Os games do primeiro PlayStation fizeram parte da minha formação, e, mais tarde, apareceram em minha produção acadêmica e artística. A questão é que a influência dos videogames reverbera até hoje em minha vida. Não se trata apenas de entretenimento vazio, e sim um labirinto de possibilidades de narrativa, imersão e interação. 


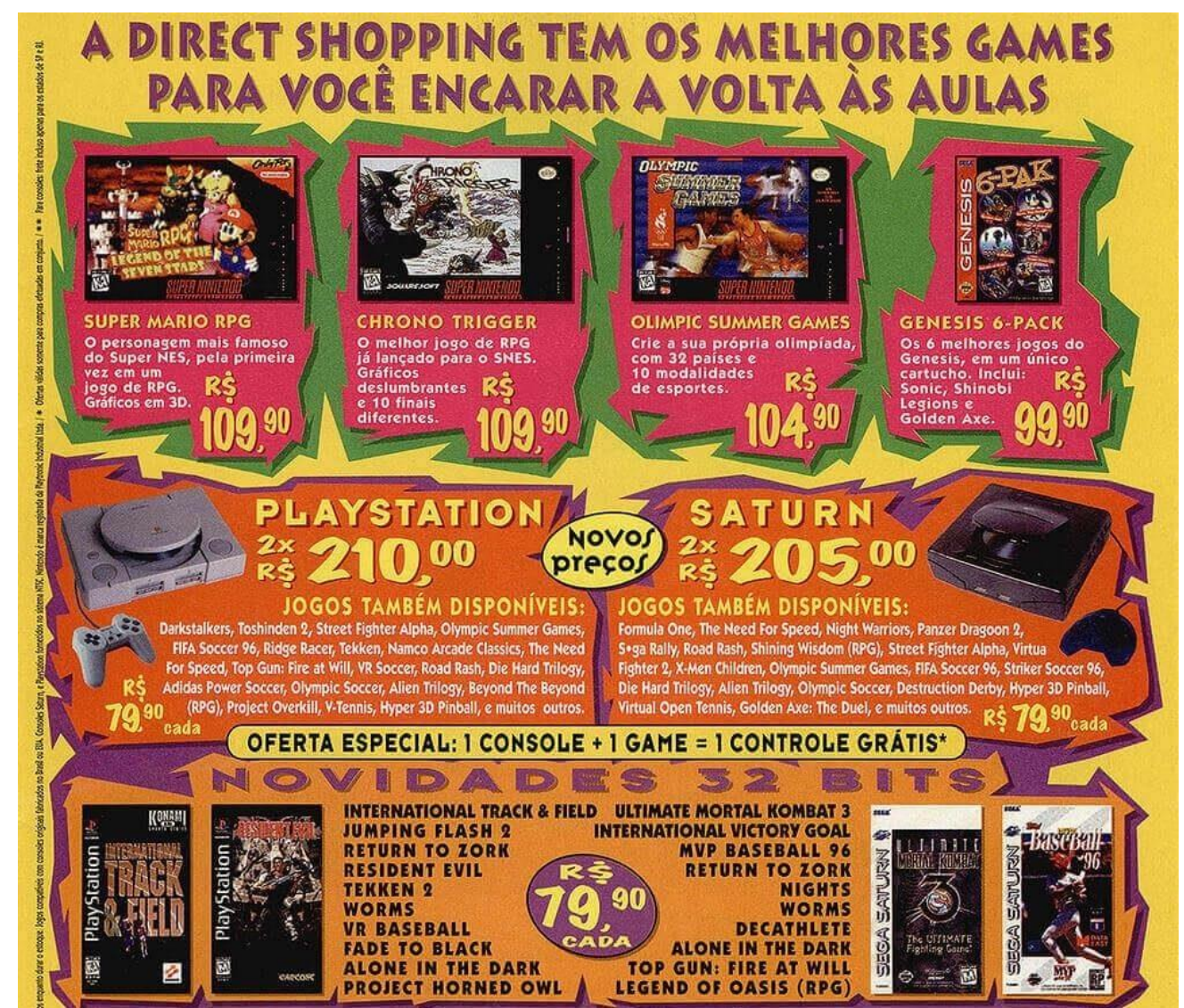

Figura 6: Valores dos videogames na década de 1990.

Fonte: https://www.facebook.com/gameads1.

\section{Imersão e interação}

Os jogos possibilitam ao jogador imergir em um determinado universo através da interação. Huizinga (2013) nomeia esse encontro de círculo mágico, um momento em que a realidade não importa, apenas o mundo do jogo. Dentro desse círculo mágico, o jogador suspende a sua crença da verossimilhança, e a realidade do jogo é aceita (AUDI, 2016). Para Audi (2016) a imersão significa uma experiência enriquecedora quando o jogador é transportado para esse espaço simulado.

Desde a antiguidade, os artistas procuram a imersão através dos mosaicos na Roma Antiga, nos afrescos no Renascimento e, posteriormente, com novas tecnologias (GRAU, 2007). Uma busca que foi extrapolada com a chegada da arte digital e, principalmente, com os videogames. Nesse nível de imersão, os jogadores são desafiados a tomar decisões assim como na vida real, e propiciam experiências e vivências de momentos que podem ser úteis no futuro (ALVES, 2008). Os jogos digitais propiciam ao jogador: imersão e interatividade.

Revista Digital do LAV - Santa Maria - vol. 14, n. 3, p. 27 - 47 - set./dez. 2021 ISSN 1983 - 7348 http://dx.doi.org/10.5902/1983734865845 
As interfaces ou HUD (Heads-Up Display) são os mediadores entre o jogador e os sistemas dos jogos (figura 7).

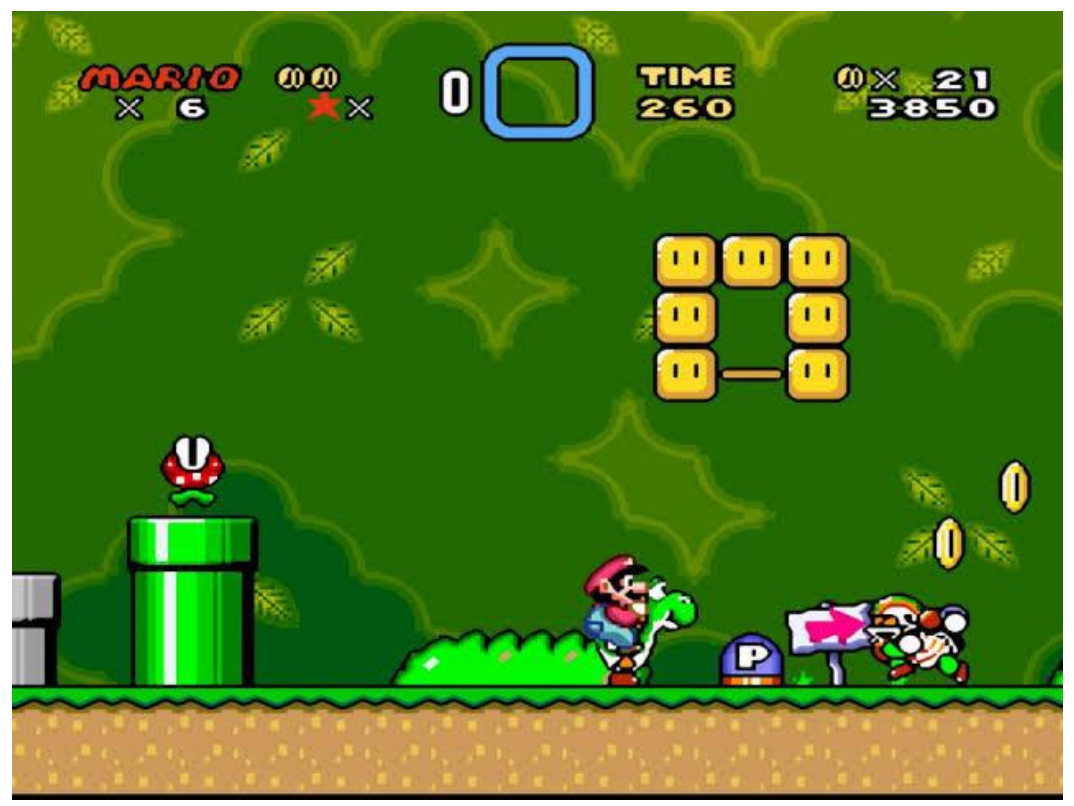

Figura 7: HUD de Super Mario World (1994) com informações sobre número de vidas, moedas e tempo para se completar a fase.

Fonte: Portal Pulo Duplo.

Esse é o modo que o jogador consegue se comunicar e ter um feedback das estruturas digitais (TONÉIS, 2012). Essas são informações que o jogador encontra na tela, como, por exemplo: mapa, objetivos, pontos de vida do personagem e dos inimigos. Nesse sentido, o processo de imersão está intrinsicamente relacionado com a interação provocada pela interface (CARRIERI; GOBIRA, 2012).

Os jogos digitais oferecem ao jogador uma maneira de vivenciar diversas experiências. Assim, os videogames existem através de um esforço interdisciplinar entre várias áreas do conhecimento. E por seu caráter interdisciplinar, também é possível ser trabalhado no ensino-aprendizagem.

\section{O professor}

Não planejei me tornar professor, tanto que sou Bacharel em Artes Visuais pela Universidade Federal de Goiás, mas, sinto que todas as minhas escolhas culminaram para a entrada na sala de aula. Durante uma visita ao PROCON, em novembro de 2020, fui atendido por um ex-aluno da $9^{\circ}$ série do ensino fundamental, um dos mais bagunceiros da turma. Estava todo contente por me rever, e fez questão de me atender e elogiar para os colegas de trabalho. Assim, conversamos durante horas enquanto a empresa de telefonia estava ausente do outro lado da linha. Em um determinado ponto, foi dito que 
entrei muito jovem em sala de aula, e, por isso, conseguia alcançar os alunos de uma maneira tão efetiva e afetiva.

Após meus primeiros meses como professor de História da Arte, descobri que um colega da instituição me deu o seguinte apelido: professor datashow. O fato de utilizar todos os recursos midiáticos disponíveis pela instituição gerou um incômodo nos que eram acostumados com métodos tradicionais de ensino. As diferenças culturais podem ser vistas como um recurso metodológico, e não uma ameaça a escola (MARTINS, 2018). Houve um preconceito, em meio às suspeitas de que as constantes idas dos alunos para a sala de multimídias era uma cortina de fumaça, e que nenhum conteúdo relevante estava sendo desenvolvido.

Em palestra, o curador Agnaldo Farias (2010) disse que o professor tem que ser tão extrovertido quanto um camelô, para persuadir seres impermeáveis sobre a importância do conhecimento. Os professores são contadores de história, pois precisamos passar para os alunos a importância de um determinado conteúdo e as suas reverberações em seus cotidianos. São recorrentes as críticas de alunos que professores não tem "didática", ou seja, que as histórias dos professores não alcançaram o seu público-alvo. É comum ouvir esse tipo de comentário dos alunos durante as aulas de Artes: "até eu faço isso". E foi exatamente o que aconteceu em uma das minhas aulas como professor de História da Arte do $2^{\circ}$ ano do ensino médio, para ser específico, durante a aula sobre abstracionismo. Como desafio, propus aos alunos que utilizassem a mesma técnica de Pollock (1921 - 1956) em uma atividade em grupo (figura 7):

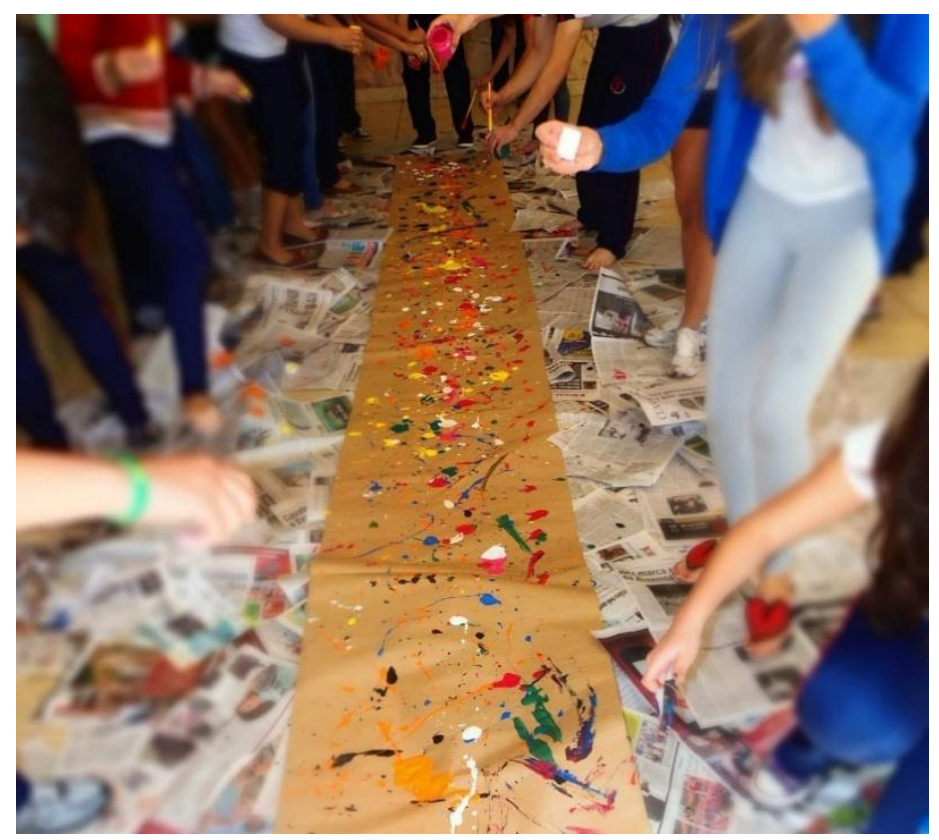

Figura 7: Aula prática sobre o abstracionismo.

Fonte: Acervo do autor.

Revista Digital do LAV - Santa Maria - vol. 14, n. 3, p. 27 - 47 - set./dez. 2021 ISSN 1983 - 7348 http://dx.doi.org/10.5902/1983734865845 
Através do gestual, a turma percebeu que não era fácil dominar a tinta, mas, enquanto isso, se divertiram bastante. O exercício foi importante para que os alunos, por um breve momento, se colocassem no papel do artista. Quando um aluno diz "até eu faço isso", acaba por reduzir a produção intelectual e o processo criativo do artista ao superficial.

Esse comentário, sobre qualquer um conseguir produzir o que o artista faz, acaba por perpetuar estereótipos. Segundo Hall (1997), o estereótipo é uma maneira de reduzir o outro a partir de poucas características, essas imutáveis e definidas pela natureza com o objetivo de separar o normal e aceitável, do anormal e do inaceitável. Para o autor, o estereótipo ocorre em contextos de poder desigual, ou seja, o detentor de poder estereotipa o outro, seja um subordinado, seja um grupo excluído (HALL, 1997). Quando apenas as superfícies se encontram, há poucas chances de descobertas e negociações, ou seja, não há diálogo entre o professor e os alunos (BAUMAN, 2003).

Essa combinação de palavras que resulta no "até eu faço isso", reduz o trabalho do artista a uma noção de que o mesmo é inferior a outras profissões, como algo marginalizado, e também coloca a produção artística como irrelevante e sem valor. Frente à isso, a possibilidade de imersão e interatividade dos jogos pode romper com estereótipos tão propagados e enraizados em nossa cultura.

Da mesma maneira que o professor é um contador de histórias, os videogames também, e todo jogo significa alguma coisa (HUIZINGA, 2013). Então, defino narrativa como uma história ordenada, que através de acontecimentos formam significados (AUDI, 2016). A narrativa dos videogames se difere de outras mídias do entretenimento, pois depende de uma interação em tempo real. Para Squire (2014), a narrativa se caracteriza como uma cadeia de signos com sentidos sociais, culturais e/ou históricos. Já Audi (2016) considera a narrativa uma união entre o conteúdo (história) e o modo (discurso). Então, para falar sobre jogos digitais, defino a narrativa como resultado da interação do jogador/usuário com a máquina através dos aspectos visuais, sonoros e de sua forma de jogar.

Nesse contexto, o professor pode utilizar os jogos digitais em prol de sua narrativa. Assim, existe a possibilidade de contar uma história (conteúdo a ser ministrado) através da narrativa pré-estabelecida dos jogos digitais. É importante ressaltar que, os jogos digitais necessitam do professor como mediador e orientador, não basta simplesmente oferecer ao aluno um game sem o devido acompanhamento. Os videogames são um caminho para o professor se atualizar em sua prática docente, contudo, isso não deve ser feito de maneira arbitrária e superficial. 


\section{O aluno}

Minhas aulas de artes no ensino fundamental foram traumatizantes. Por isso, aprendi logo cedo como não se portar em uma sala de aula. Por exemplo, na minha oitava série, a professora de artes se aproximou, viu, rasgou e jogou fora um desenho de minha autoria. No papel, havia desenhado o personagem Goku, da série animada Dragon Ball (1989 - 2015). Para essa professora, que também ministrava a aula de Ensino Religioso, aquele personagem contrariava as suas crenças e deveria ser exterminado da sala de aula. Hoje, compreendo que essa professora não tinha uma formação adequada para ministrar uma aula de artes.

Também havia um conflito de gerações, pois cresci com acesso a videogames, filmes, animes e histórias em quadrinhos (figura 8). Essas mídias foram responsáveis por me incentivar na produção artística, mas, para gerações anteriores isso poderia significar um desvio do caminho correto. Esses conflitos geracionais são comuns, e já aconteceram em diversos momentos e com diversas mídias, como por exemplo as histórias em quadrinhos, o Rock e o Metal e, posteriormente, com os videogames sendo acusados de desvirtuar e influenciar negativamente a juventude. Para Nóbrega et al. (2011) há professores que estabelecem uma relação de conflito entre tecnologia, mídia e educação, um pensamento reducionista e limitador de ações em sala de aula.

Em minha trajetória como aluno (ensino básico, superior e pós-graduação), acabava por me aproximar dos professores que apresentavam uma conexão com o que eu gostava. Isso pode parecer irrelevante, mas esse elo fortalecia meu interesse pelas matérias, além de também ser um incentivo para ousar e ser criativo na apresentação de trabalhos e no fazer artístico. Esses professores se apropriavam de linguagens diversas para conseguir acessar a realidade dos alunos. Esses, muitas vezes cansados, sonolentos e também estressados pelas cobranças da vida contemporânea. Nesse sentido, os jogos são uma oportunidade para fortalecer laços de confiança entre o professor e o aluno, e facilitar a comunicação e interesse pelo conteúdo das disciplinas. 


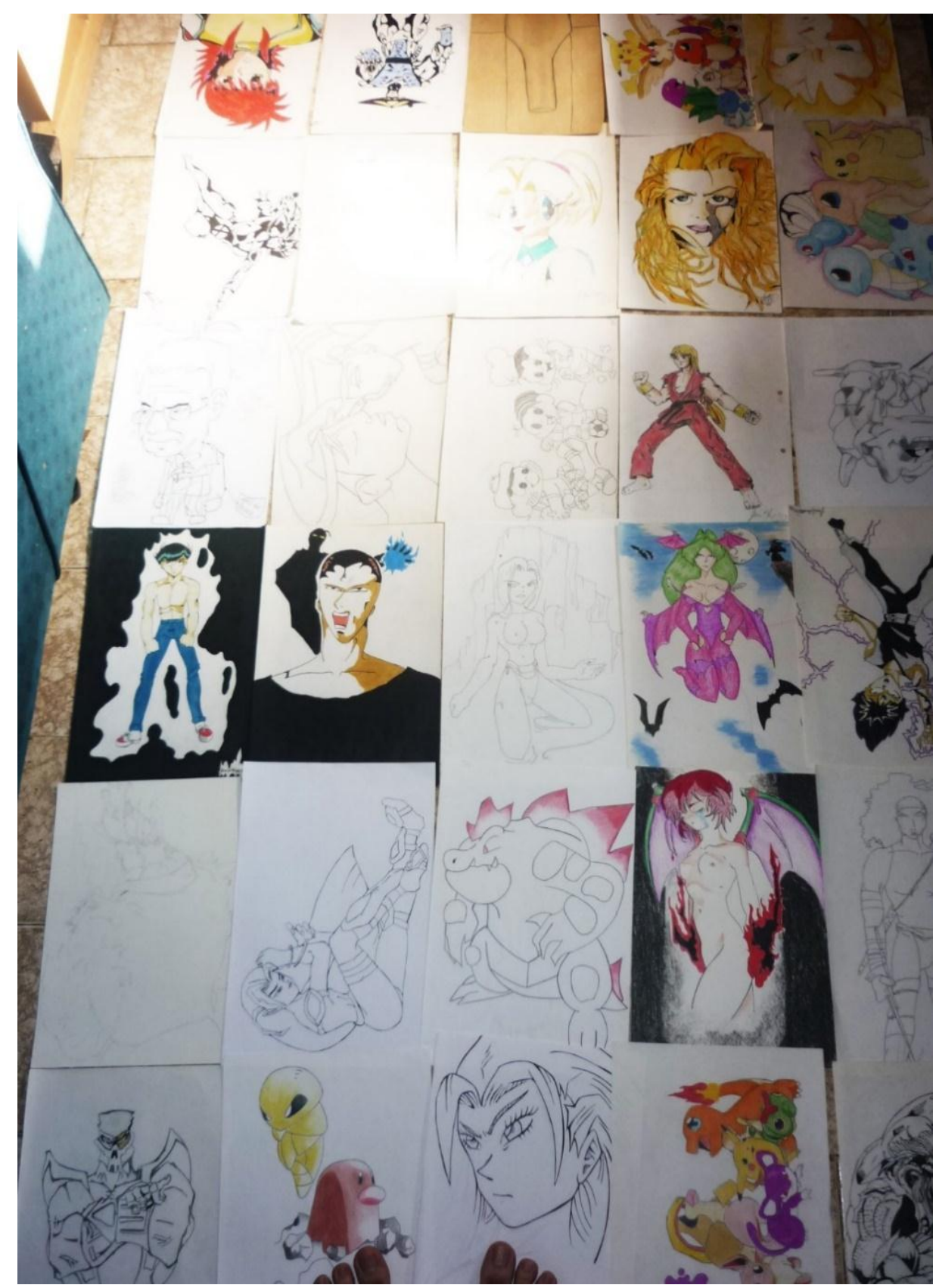

Figura 8: Desenhos feitos na infância.

Fonte: Acervo do autor.

\section{Acesso e diversão}

Vilém Flusser (1963) define diversão como aversão ao universo. Para o autor, a diversão confronta a noção de converter todos os elementos desse único "verso", que busca um controle "instrumentalizante" da vida. Nesse contexto, a palavra diversão busca uma diversidade de experiências, além das impostas pelas demandas da vida contemporânea. Quando chegava da escola, a primeira coisa que fazia era almoçar e a segunda era ligar o meu videogame. A diversão ocasionada pelo PlayStation produzia um 
alívio e uma sensação catártica de, por algumas (muitas) horas, ser transportado para um universo mais interessante e com regras mais claras, ou seja, menos apegado às regas do nosso mundo.

Destaco que, se antigamente um videogame custava um salário mínimo, em 2021, um PlayStation 5 e Xbox Séries X - videogames da nova geração, custam aproximadamente cinco salários mínimos. Ter acesso a um videogame ou/e um computador voltado para jogos significa ser privilegiado. A tecnologia deve ser usada com o objetivo de inclusão e não exclusão, algo que conheço bem ao longo da minha trajetória como estudante. Passei por várias situações desconfortáveis em minha graduação em Artes Visuais pela Universidade Federal de Goiás, e as principais envolviam não ter recursos financeiros para a compra de materiais. Em 2008, desisti de cursar uma disciplina sobre Aquarela, motivo: os materiais requisitados pela professora custavam em torno de $\mathrm{R} \$ 300$. Para se ter uma ideia, o salário mínimo nesse período era de $\mathrm{R} \$ 415$, ou seja, um valor absurdo para a maioria dos estudantes do curso de Artes Visuais. Assim, a professora estava distante da minha realidade, e da de outros colegas, pois não se atentou ao alto custo dos materiais.

Consequentemente, passei por situações incômodas em meu doutorado em Artes Visuais pela Universidade de Brasília. Em 2016, durante a apresentação do trabalho de um colega, havia a necessidade do uso de um smartphone, e apenas assim o público poderia fruir a obra. Entretanto, eu era o único da turma que não possuía um aparelho do tipo, ou seja, fiquei de lado por não ter os materiais necessários. O mesmo aconteceu durante outra aula, pois o professor exigiu que os alunos levassem seus notebooks para se ter uma aula sobre programação básica. A aula se iniciou com a turma colocando seus caros notebooks de alta performance sobre a mesa. Contudo, eu não tinha (e ainda não tenho) um computador portátil, sendo assim, fui obrigado a sentar com uma colega. A poucos metros da sala de aula existe um laboratório da instituição, ou seja, o professor poderia ter usado aqueles computadores.

Temos a possibilidade de utilizar os games para criar um vínculo entre diversas gerações. Uma oportunidade para atualizar os processos de ensino e cativar os alunos. Existe a possibilidade dessa prática funcionar, desde que o educador se atente a uma questão fundamental: o conseguir jogar. Um dos pontos fundamentais de um jogo digital é a relação com o jogador/usuário. A jogabilidade é definida pelo conjunto de ações e interações entre o jogador e os componentes do jogo digital, como por exemplo os aspectos audiovisuais, emotivos e cognitivos (XAVIER, 2010). Tão importante quando a jogabilidade é o jogador ter acesso e conseguir usufruir daquele jogo. Vivemos em um país que ocupa a $8^{\circ}$ posição dos mais desiguais do mundo (AMORIM; MADEIRO, 2020). Tive o privilégio 
de ter contato com diversos videogames ao longo da minha trajetória, mas isso é uma realidade de poucos. Esse é provavelmente o maior desafio do uso de jogos digitais no ensino.

\section{Os games e as possibilidades no ensino de Artes Visuais}

A experiência proporcionada pelos games tem como foco principal o usuário, ou seja, o jogador. Todas as mecânicas e decisões sobre a forma de jogar, narrativa e imersão têm como objetivo proporcionar uma experiência ao jogador. Assim, nesse contexto, defendo o uso de metodologias ativas centradas na experiência e realidade do aluno. Não basta desenvolver e planejar uma aula sem conhecer o outro, e talvez por isso que vejamos sistematicamente um conflito geracional entre professores e alunos. Os videogames e o ensino-aprendizagem não existem sem a presença ativa do jogador/aluno. Aqueles que nasceram após 1980 são considerados nativos digitais, ou seja, tiveram seu desenvolvimento biológico e social em contato direto e constante com a tecnologia. Contudo, assim como o videogame não é tão acessível a todos, existem gerações de crianças e adolescentes que ainda não estão inseridos no universo digital. Atualmente, os alunos considerados nativos digitais são capazes de hipertextualizar várias coisas ao mesmo tempo (ALVES, 2007). Contudo, existem diversos níveis desse contato tecnológico, de acordo com a vivência de cada sujeito. A sétima edição da Pesquisa Game Brasil revelou que $73,4 \%$ dos brasileiros jogam jogos digitais, em videogames, computadores e aparelhos móveis (SIOUX; BLEND; ESPM, 2020).

Os artistas, ao longo da História da Arte, se entregavam ao experimentalismo em seu processo criativo. $\mathrm{Na}$ atualidade, os jogadores consomem jogos dos mais diversos gêneros e nas mais variadas plataformas. O jogador também pode ocupar o papel de aluno e professor. Os games estão se consolidando em nossa cultura, contudo, ainda é um bem material fruto do sistema capitalista. Então é importante nos questionarmos: por que não se apropriar dos jogos digitais no processo de ensino-aprendizagem?

Atualmente, apenas uma área do conhecimento não consegue resolver toda a complexidade que envolve os jogos digitais. Para Paiva e Tori (2017) essa amplitude favorece a utilização de vários campos do conhecimento simultaneamente. Os jogos digitais são construídos para que o jogador possa resolver problemas através da repetição de ações. Vivenciar situações de conflito que exigem tomadas de decisões, podem criar estratégias metodológicas para a formação de estudantes em diversos níveis de ensino (ALVES, 2008). Nesse sentido, podemos atribuir esse processo no contexto social e cultural. Assim, os jogos no ensino-aprendizagem podem estimular a investigação e a 
exploração através de experiências individuais e em grupo (CONTRERAS-ESPINOSA; EGUIA-GÓMEZ; HILDEBRAND, 2013).

Os alunos podem construir suas próprias realidades e organizar seus conhecimentos e, ainda, podem vivenciar experiências ficcionais e internalizar sistemas reais, estratégicos e de risco, através dos jogos digitais. De fato, esta abordagem, com este tipo produção, pode ser transferida e aplicada às situações reais de vida (CONTRERASESPINOSA; EGUIA-GÓMEZ; HILDEBRAND, 2013, p. 205).

Um dos maiores desafios para um professor em seu processo de contar histórias é convencer o aluno de que aquele conhecimento é importante. Então, para corroborar com Agnaldo Farias (2010), o professor/camelô precisa demonstrar como um conhecimento transborda para além da sala de aula, que está presente constantemente em nosso cotidiano.

O desafio do professor está em planejar, para que suas ações não sejam percebidas como apenas entretenimento, sem objetivos educacionais. Os pesquisadores Contreras-Espinosa, Eguia-Gómez e Hildebrand (2013), através de um estudo de caso, estabeleceram algumas recomendações importantes para que os professores possam utilizar os jogos digitais de maneira efetiva em sala de aula: O professor deve liderar a iniciativa; contar com o apoio das instituições; criar um planejamento escolar dedicado ao uso de jogos; criar redes de apoio para o sucesso do projeto a longo prazo; utilizar de métodos para que o aluno possa mostrar as habilidades adquiridas ao jogar; e incentivar que o jogo utilizado em sala de aula seja jogado entre pais e alunos. Também considero o contexto econômico como decisivo e que deve ser levado em consideração para os profissionais que pretendem utilizar os games em sala de aula. Para Nóbrega et al. (2011) algumas perguntas podem auxiliar o professor, como por exemplo: Quais os conteúdos abordados? Qual a melhor forma de apresentação? Qual o jogo? Quais competências são desenvolvidas? Já Paiva e Tori (2017) colocam como principais desafios: os jogos educacionais mal estruturados, as lacunas na formação docente e a perda de espontaneidade.

Essas são questões fundamentais para a aplicação dos jogos digitais no ensinoaprendizagem, como por exemplo o custo de um videogame. As propostas precisam ser moldadas através das possibilidades estruturais (hardware, software e humanas). É importante observar as diversas perspectivas, para que os jogos digitais sejam utilizados de maneira objetiva, visando a inclusão de todos os envolvidos nesse processo: professores, alunos, instituição e familiares. 
O professor precisa ter domínio teórico e discursivo, pois trabalhar com jogos em sala de aula é, por muitas vezes, lidar com barreiras institucionais, culturais e sociais. Para Lynn Alves, Mariá Scárdua e Piero Baptista (2009, p. 4):

Se o objetivo maior do conhecimento e da educação é formar pessoas capazes de valorar positivamente suas relações pessoais e interpessoais, esta tem que criar espaço para si neste cenário contemporâneo, necessariamente, ou correr o risco de estar associada com valores ou métodos caducos. A informação tem que ser clara, engajada e bem colocada em seu devido contexto, aproximando o conhecimento dos jovens de modo que possa estar associado a algo rico, dinâmico e atrativo.

O professor tem a possibilidade de conhecer a realidade e as vivências de seus alunos, e assim planejar ações que envolvam a utilização de jogos digitais. Nesse sentido, os jogos digitais criam um diálogo contínuo entre professor e aluno, ou seja, sujeitos que vivem em diferentes espaços de aprendizagem (ALVES, 2008). Para Nóbrega et al. (2011), a utilização de games no ensino de Artes Visuais se mostra frutífera, pois enquanto uma mídia audiovisual podemos abordar e problematizar os aspectos plásticos, estéticos, teóricos e práticos. De acordo com os autores, de maneira lúdica, os games permitem abordar questões reflexivas e abstratas.

Em 2012, durante as minhas aulas de História da Arte, utilizei games que dialogaram com o conteúdo desenvolvido em sala de aula. Por exemplo, nas aulas sobre a Grécia Antiga, recomendei Age of Mythology (2002) - jogo de estratégia em tempo real sobre a cultura e mitologia grega ${ }^{4}$. O aluno pode conhecer mais da cultura da Grécia Antiga através das construções arquitetônicas e da religião por meio da narrativa do jogo. Já nas aulas sobre as vanguardas artísticas no século XIX, utilizei Avant-garde (2013) - jogo independente desenvolvido para navegadores e pertencente ao gênero RPG (Role-Playing Game ${ }^{5}$ ), em português: jogo de interpretação de papéis. Nesse jogo, os alunos poderiam interpretar um artista recém-chegado a Paris, que deveria pesquisar materiais, estudar técnicas, produzir trabalhos artísticos, se relacionar com diversos artistas do período e participar do Salão de Belas Artes de Paris.

Os games estão se tornando cada vez mais presentes na educação e na formação de crianças e adultos. Contudo, o professor deve fazer escolhas críticas para evitar jogos

\footnotetext{
${ }^{4}$ Alguns exemplos desse gênero são: Age of Empires (1997), Warcraft III: Reign of Chaos (2002), The Lord of the Rings: The Battle for Middle Earth (2004), Star Wars: Empire at War (2006), StarCraft II: Wings of Liberty (2010), Iron Harvest (2020).

${ }^{5}$ Alguns exemplos desse gênero são: Chrono Trigger (1995), Terranigma (1995), Diablo (1997), Final Fantasy Tactics (1997), Suikoden II (1998), Valkyrie Profile (1999), Pokémon Silver (1999), Xenoblade Chronicles (2010), e Pillars of Eternity II: Deadfire (2018) e Baldur's Gate III (2020).
} 
que enalteçam a violência, consumo desenfreado e supervalorização da aparência (NÓBREGA et al., 2011).

Os alunos também mostravam interesse sobre o que estava no entorno, por exemplo filmes, livros, histórias em quadrinhos e podcasts sobre o conteúdo da aula. Assim, compartilhar e discutir sobre games em sala de aula abria a possibilidade de conhecer a realidade e o cotidiano de cada um dos meus alunos. Dessa maneira, os jogos favorecem o aprendizado tangencial, pois existe o aprendizado espontâneo, não apenas no momento em que o professor pretende ensinar um determinado conteúdo (PAIVA; TORI; 2017), mas em suas reverberações futuras.

\section{Considerações finais}

Em 1958, William Higinbotham criou o primeiro jogo digital, o Tennis for Two, e, desde então, sucessivas gerações acompanharam a evolução tecnológica dos videogames. Assim, os games já estão se fundamentando em nossa cultura e em nosso cotidiano. Isso é um rompimento de paradigmas, em que se atesta que jogos digitais são efêmeros e desprovidos de mensagens. Aprender e desenvolver as possibilidades dos games em sala de aula é uma maneira de manter o diálogo entre diferentes gerações de educandos e educadores. É um caminho efetivo para o diálogo entre professores e alunos e uma relação mais próxima entre diversas vivências. Parto da compreensão de que os games também são arte, e, assim, cabe ao professor mediar o contato e a fruição entre obra, aluno e conhecimento.

Os games podem auxiliar o contato dos alunos com a arte contemporânea, tão renegada nos livros didáticos. Já que a linguagem é pesquisada e usada por artistas com os mais diversos temas e objetivos. Mas, também podem ser utilizados para o desenvolvimento de conteúdos sobre as Artes Visuais. Os videogames não devem ser vistos como adversários pela atenção do aluno, mas como um recurso a ser apropriado pelos professores.

Desde 2013, ocupo concomitantemente o papel de artista, jogador, professor e aluno. E durante esse período, aprendi como somos diversos e podemos aprender com cada uma de nossas facetas. $O$ artista pode estimular a criatividade do professor, enquanto o jogador pode incentivar a inovação e a investigação no aluno, ao mesmo tempo em que o aluno busca diversão assumindo um arquétipo de jogador, e, por fim, o professor pode aprender com todos. Os videogames abrem portais para outros mundos, mas também para conhecer a realidade do outro. Nesse sentido, ocupamos diversos papéis ao longo da vida, 
como por exemplo: artista, jogador, professor e aluno. Contudo, existe o risco de esquecermos de como é estar do outro lado, e por muitas vezes diminuir a perspectiva e vivências do outro.

\section{Referências}

ALVES, L. Games e educação - a construção de novos significados. Revista Portuguesa de Pedagogia, 2008, Bahia, p. 225 - 236. Disponível em: <https://impactumjournals.uc.pt/rppedagogia/article/view/1647-8614_42-2_12>. Acesso em: 3 out. 2020.

ALVES, L. Nativos digitais: games, comunidades e aprendizagens. Em: MORAES, Ubirajara Carnevale de. (Org.). Tecnologia Educacional e Aprendizagem: o uso dos recursos digitais. Livro Pronto: São Paulo, 2007, p. 233-251.

ALVES, L.; SCÁRDUA, M.; BAPTISTA, P. Games, arte e educação: considerações gerais. 2009. SIMPÓSIO BRASILEIRO DE JOGOS E ENTRETENIMENTO DIGITAL, VIII, Rio de Janeiro. Anais..., Rio de Janeiro (RJ), p. 1 - 5, 2009.

AMORIM, F.; MADEIRO, C. Brasil tem a $8^{\mathbf{a}}$ pior desigualdade de renda e supera só países africanos. $U 2$ 2020 Disponível em: <https://noticias.uol.com.br/internacional/ultimas-noticias/2020/12/15/brasil-tem-a-8pior-desigualdade-de-renda-e-supera-so-paises-africanos.htm >. Acesso em: 17 dez. 2020.

AUDI, G. Imergindo no mundo do videogame. Curitiba: Editora Appris, 2016.

BAUMAN, Z. Comunidade: a busca por segurança no mundo atual. Rio de Janeiro: Jorge Zahar Ed., 2003.

CARRIERI, A.; GOBIRA, P. Jogos e sociedade: explorando as relações entre jogo e vida. Minas Gerais: Editora Crisálida, $1^{\text {a }}$ Ediç̧̃ão, 2012.

CONTRERAS-ESPINOSA, R.; EGUIA-GÓMEZ, J.; HILDEBRAND, H. Aprendizagem baseada em Jogos Digitais: Entrevistas com professores que utilizam jogos digitais em suas práticas educativas. Em: Anais do SBC - Proceedings of SBGames e XII Simpósio Brasileiro de Jogos e Entretenimento Digital, 2013, São Paulo (SP), p. 204 - 210. Disponível em: <http://www.sbgames.org/sbgames2013/proceedings/cultura/Culture-26_full.pdf>. Acesso em: 20 set. 2020.

FARIAS, A. Entre Homero e Platão: Agnaldo Farias at TEDxUSP. TEDX Talks. Youtube TEDx Talks. 2010. Disponível em: <https://youtu.be/JQcfrgU_kqY>. Acesso em: 2 set. 2020.

FLUSSER, V. Da diversão. Portal Flusser Brasil. 1963. Disponível em: <http:flusserbrasil.com/art303.pdf>. Acesso em: 17 dez. 2020.

GRAU, O. Arte Virtual: da ilusão à imersão. Trad. Cristina Pescador, Flávia Gisele Saretta, Jussânia Costamilan. São Paulo: UNESP: Senac São Paulo, 2007.

HALL, S. The spectacle of the "other". In: Representation: Cultural Representations and Signifying Practices. Londres: Sage, 1997. p. 223 - 290.

Revista Digital do LAV - Santa Maria - vol. 14, n. 3, p. 27 - 47 - set./dez. 2021 ISSN 1983 - 7348 http://dx.doi.org/10.5902/1983734865845 
HUIZINGA, J. Homo ludens: o jogo como elemento da cultura. São Paulo: Perspectiva, 2013.

LEÃO, L. Cultura dos jogos, gamearte e os exercícios da webmatilha. Em: Simpósio da ciberarte à gamearte [ou da cibercultura à gamecultura]. SESC: Pompeia. 2005.

MACHADO, A. Arte e mídia. Rio de Janeiro: Zahar, 2007.

MARTINS, R. Conversando Sobre Estudos Críticos e Educação. CIAR - Universidade Federal de Goiás, 2018. Disponível em: <https://producao.ciar.ufg.br/ebooks/licenciaturaem-artes-visuais/modulo/2/html $\geq$. Acesso em: 20 abr. 2020.

MASTROBERTI, P. Ludopoéticas: Relações possíveis entre jogo, arte e educação a partir de ações de pesquisa. SIMPÓSIO BRASILEIRO DE JOGOS E ENTRETENIMENTO DIGITAL, XVIII. 2019, Rio de Janeiro. Anais..., Rio de Janeiro (RJ), p. 1025 - 1033.

NÓBREGA, C. et al. Gameduca: criação de jogos digitais para o ensino da história da arte. ASSOCIAÇÃO NACIONAL DE PESQUISADORES EM ARTES PLÁSTICAS, 2011, Rio de Janeiro. Anais..., Rio de Janeiro (RJ), 2011.

PAIVA, C. A.; TORI, R. Jogos digitais no ensino: processos cognitivos, benefícios e desafios. SIMPÓSIO BRASILEIRO DE JOGOS E ENTRETENIMENTO DIGITAL, XVI. 2017, Curitiba. Anais..., Curitiba (PR), 2017.

SARDELICH, M.; SANTOS, N. Interpretação e Compreensão de Imagens. 2008. (Desenvolvimento de material didático ou instrucional - Material Didático para Educação a Distância). Disponível em: <https://publica.ciar.ufg.br/ebooks/licenciatura-em-artesvisuais/modulo/5/002.html $\geq$. Acesso em: 13 out. 2020.

SIOUX; BLEND; ESPM. Pesquisa Game Brasil 2020. Disponível em: <https://www.pesquisagamebrasil.com.br/pt/z. Acesso em: 6 set. 2020.

SOUZA, J. Paradigm shift: uma aventura em busca do jogo. $2^{\circ}$ edição. Joinville: Editora Clube dos Autores, 2016.

SQUIRE, C. O que é narrativa? Em: Revista Civitas, v. 4, n. 2, maio-agosto, 2014, p. 272 $-284$.

TONÉIS, C. Experiência estética e a interface nos jogos digitais: a produção de um edutainment game - Lua. Em: Revista Tecnologia e Sociedade, 2012, p. 150 - 165.

VENTURELLI, S.; MACIEL, M. Gamearte: uma poética de interação. Em: Revista FAMECOS, v. 1, p. 4, 2004.

XAVIER, G. A condição eletrolúdica: cultura visual nos jogos eletrônicos. Teresópolis: Editora Novas Ideias, 2010.

\footnotetext{
' Artista multimídia, professor de Histórias em Quadrinhos, e produtor cultural. Doutor em Artes pela Universidade de Brasília (UnB). Mestre em Arte e Cultura Visual pela Universidade Federal de Goiás (UFG). Trabalha na linguagem da arte computacional, histórias em quadrinhos, webarte, fake arte e gamearte. Também pesquisa sobre transhumanismo, jogos de tabuleiro, cibercultura, sexualidade e práticas divinatórias.
} 
Membro do Coletivo Interdisciplinar de Pesquisa em Games (CIPEG) e professor de Artes no Instituto Federal de Educação, Ciência e Tecnologia São Paulo (IFSP).

Como citar esse artigo:

LOURES, José. Reflexões sobre o uso de games no ensino de arte a partir do artista, jogador, professor e aluno. Revista Digital do LAV, Santa Maria: UFSM, v. 14, n. 3, p. 27-47, set./dez. 2021. 